\title{
Thermal and Photo-Induced Reactions of Polymer Radicals in $\gamma$-Irradiated Poly(alkyl methacrylate)
}

\author{
Migaku TaNaKa, Hiroshi Yoshida, and Tsuneki ICHIKaWA* \\ Faculty of Engineering, Hokkaido University, \\ Kita-ku, Sapporo 060, Japan
}

(Received April 5, 1990)

\begin{abstract}
Thermal and photo-induced reactions of radical species generated by $\gamma$-irradiation of poly(methyl methacrylate) and poly(ethyl methacrylate) have been investigated by means of ESR spectroscopy. The $\gamma$-irradiation at cryogenic temperature leads to the formation of three major radical species, side chain $-\mathrm{COOC}_{n} \mathrm{H}_{2 n+1}{ }^{-}$anion radicals and $-\mathrm{COOCHC} \mathrm{C}_{n-1} \mathrm{H}_{2 n-1}$ radicals, and main chain $-\mathrm{CH}$ - radicals. Cation radicals are immediately converted to the neutral radicals by proton transfer to the polymer molecules. Illumination of the polymer anion radicals with visible light leads to electron detachment or the elimination of ester alkyl groups to form alkyl radicals. Illumination with $\mathrm{UV}$ light leads to the conversion of the $-\mathrm{COOCHC}_{n-1} \mathrm{H}_{2 n-1}$ radicals to acyl-type $-\mathrm{C}=\mathrm{O}$ radicals. Both the $-\mathrm{COOCHC}_{n-1} \mathrm{H}_{2 n-1}$ and the $-\mathrm{C}=\mathrm{O}$ radicals are the precursor of scission-type $\mathrm{C}\left(\mathrm{CH}_{3}\right)\left(\mathrm{COOC}_{n} \mathrm{H}_{2 n+1}\right) \mathrm{CH}_{2}-$ radicals.
\end{abstract}

KEY WORDS Poly(methyl methacrylate) / Poly(ethyl methacrylate) / Resist /

Lithography / Radiolysis / Degradation / Chain scission / Radical / ESR /

Since poly(alkyl methacrylate)s are typical positive-resist materials in deep UV, electron beam and X-ray lithography, many studies have been carried out for clarifying the mechanism of radiation-induced degradation of poly(alkyl methacrylate)s. It is well known that the irradiation of poly(alkyl methacrylate)s with lonizing radiations results in the formation of scission-type radicals $^{1-3}$ C$\left(\mathrm{CH}_{3}\right)\left(\mathrm{COOC}_{n} \mathrm{H}_{2 n+1}\right) \mathrm{CH}_{2}-$. The formation of the scission-type radicals strongly suggests that the degradation is induced by the reaction of polymer radicals.

Since ionization is the main action of ionizing radiations, radiation-generated positive and negative ion radicals are thought to play important roles in the degradation of the polymers. A considerable amount of spectroscopic studies have been carried out for elucidating the nature and the roles of primary ion rad-

\footnotetext{
* To whom correspondence should be addressed.
}

icals in the degradation of the polymers. ${ }^{4-10}$ However, there have been few consistencies between investigators even for the spectroscopic assignment of the ion radicals. We have recently made the pulse radiolysis studies of poly(alkyl methacrylate) solutions, and determined the optical absorption bands of the polymer anion radicals. ${ }^{11}$ We have also made the ESR and electron spin echo studies of $\gamma$ irradiated poly(methyl metacrylate) (PMMA) and found that the $\gamma$-irradiation at cryogenic temperature leads to the formation of three major radical species, side chain $-\mathrm{COOCH}_{3}{ }^{--}$ anion radials and $-\mathrm{COOC}^{\mathrm{C}} \mathrm{H}_{2}$ radicals, and main chain - $\dot{\mathrm{C}} \mathrm{H}$ - radicals. ${ }^{12}$ Upon annealing the polymer to room temperature, the $-\mathrm{COOCH}_{2}$ radicals were disappeared accompanied by the formation of scission-type $\mathrm{C}\left(\mathrm{CH}_{3}\right)\left(\mathrm{COOCH}_{3}\right) \mathrm{CH}_{2}$ - radicals, which suggests that the $-\mathrm{COOCH}_{2}$ radicals are respon- 
sible for the scission of polymer main chains. However the mechanism of radical conversion from the precursor radicals to the scission-type radicals is yet unclear.

In the present study, the thermal and photo-induced reactions of polymer radicals in $\gamma$-irradiated PMMA and poly(ethyl methacrylate) (PEtMA) have been studied by means of ESR spectroscopy for elucidating the mechanism of the radiation-induced degradation. It is shown that the polymer radicals with the unpaired electron on the ester side chains are thermally converted to tertiary alkyl radicals via detachment of the side chain, and the tertiary alkyl radicals are spontaneously converted to the scission-type radicals via $\beta$-scission of the polymer main chains.

\section{EXPERIMENTAL}

PMMA and PEtMA were prepared by radiation-induced polymerization of purified monomers at room temperature with ${ }^{60} \mathrm{Co}$ $\gamma$-rays. The crude polymers were purified by repeated reprecipitations from acetone solutions, and dried under vacuum ( $c a .10^{-5}$ Torr) fo one week for removing the residual solvent and monomers. The resultant polymer powders were introduced into high purity quartz tubes, degassed under vacuum for 24 hours and then sealed under vacuum. Methyl pivalate and ethyl pivalate (Aldrich Co., Ltd.), model compounds of PMMA and PEtMA, respectively, were ussed as received. These samples were degassed with several freezing-pumpingthawing cycles, and then sealed in quartz tubes. Unless otherwise stated, the samples were $\gamma$-irradiated at $77 \mathrm{~K}$ in the dark to a dose of $5.0 \mathrm{kGy}$. ESR measurements were carried out at $77 \mathrm{~K}$ on a Varian E109 X-band spectometer. The irradiated samples were thermally annealed to room temperature and/or photoilluminated at $77 \mathrm{~K}$ with visible light from a tungsten lamp and UV light from a $200 \mathrm{~W}$ mercury-xenon lamp.

\section{RESULTS AND DISCUSSION}

Figure 1 shows the ESR spectra of $\gamma$-irradiated PMMA at $77 \mathrm{~K}$. The initial spectrum (Figure 1a) has already been assigned to the superposition of four major spectral components: side chain $-\mathrm{COOCH}_{3}{ }^{\cdot-}$ anion radicals (a broad singlet at the center of the spectrum) and $-\mathrm{COOC}_{2}$ radicals (a triplet with a hyperfine coupling constant (hfcc) of $2 \mathrm{mT}$ ), main chain - $\mathrm{CH}$ - radicals (a doublet with a hfcc of $2 \mathrm{mT}$ ), and methyl radicals (a quartet with a hfcc of $2.3 \mathrm{mT}$ ). ${ }^{12}$ Illumination of the sample with visible light for $30 \mathrm{~min}$ leads to the complete disappearance of the anion radicals and the increase of methyl radicals by following reactions. ${ }^{10,12}$

$$
\begin{aligned}
& -\mathrm{COOCH}_{3}{ }^{--}+h v \rightarrow-\mathrm{C}-\mathrm{COOCH}_{3}+\mathrm{e}^{-} \\
& -\mathrm{COOCH}_{3}{ }^{-}+h v \rightarrow-\mathrm{C}-\mathrm{COO}^{-}+\mathrm{CH}_{3}
\end{aligned}
$$

Although the spectral intensity of the photogenerated methyl radicals shown in Figure $1 \mathrm{~b}$
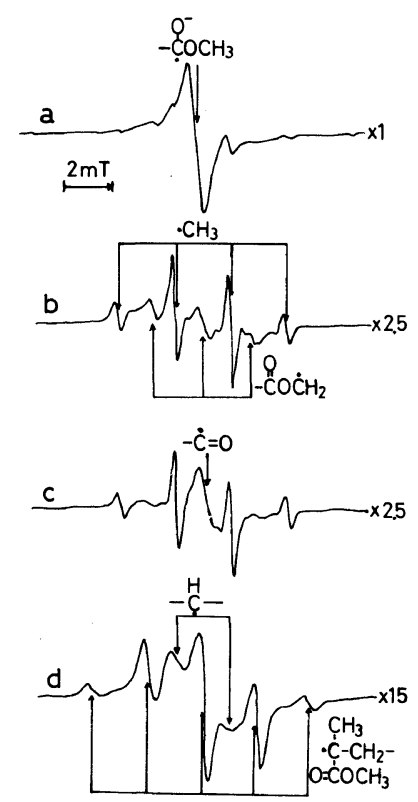

Figure 1. ESR spectra of $\gamma$-irradiated PMMA recorded at $77 \mathrm{~K}$ (a) without further treatment, (b) after visible light-illumination for $30 \mathrm{~min}$, (c) after subsequent UV light-illumination for $90 \mathrm{~min}$, and (d) after subsequent thermal annealing to room temperature for $10 \mathrm{~min}$. 
is quite strong, because of their nallow ESR line width, the actual concentration of the methyl radicals is only $10 \%$ of the original anion radicals.

As shown in Figure 1c, further UVirradiation to the visible light-illuminated sample results in the formation of new radical species with a broad singlet ESR spectrum at the expense of the $-\mathrm{COOC}_{2}$ radicals. Although the ESR spectrum of the new radical species is similar to that of the anion radicals, the spectrum is slightly shifted to the higher magnetic field. The $g$ factors of the spectra are roughly 2.000 and 2.003 for the new radicals and the anion radicals, respectively. UVIrradiation of the sample without $\gamma$-irradiation gives the ESR spectrum similar to Figure 1c, though the intensity of the spectrum is much lower than that of the $\gamma$-irradiated one. Thermal annealing of the $\gamma$-irradiated and then UV-irradiated sample to room temperature for more than a few minutes results in the conversion of the new radicals to the scission-type radicals (Figure 1d). The spectral shape and intensity of the annealed samples without visible and/or UV light-illumination are the same as the UV-irradiated one, which indicates that both the new radicals and the $-\mathrm{COOCH}_{2}$ radicals are the precusor of the scission-type radicals.

Huddson and Williams studied the radiolysis of carboxylic esters and found that $\mathrm{R}$ COOĆ $\mathrm{HC}_{n-1} \mathrm{H}_{2 n-1}$ radicals are photodecomposed into acyl-type radicals by UV irradiation, ${ }^{13}$ as

$$
\begin{aligned}
\mathrm{R}-\mathrm{COOC}^{-} \mathrm{HC}_{n-1} \mathrm{H}_{2 n-1} \\
\rightarrow \mathrm{R}-\dot{\mathrm{C}}=\mathrm{O}+\mathrm{C}_{n-1} \mathrm{H}_{2 n-1} \mathrm{CHO}
\end{aligned}
$$

The acyl-type radical is a $\sigma$-type radical with the unpaired electron weakly interacting with alkyl protons, so that it gives a broad singlet ESR spectrum $(g \simeq 1.996)$ with unresolved hyperfine structures. ${ }^{14}$ Thus, the new radicals appearing after the UV-irradiation of the $\gamma$-irradiated PMMA can be assigned to $-\mathrm{C}=\mathrm{O}$
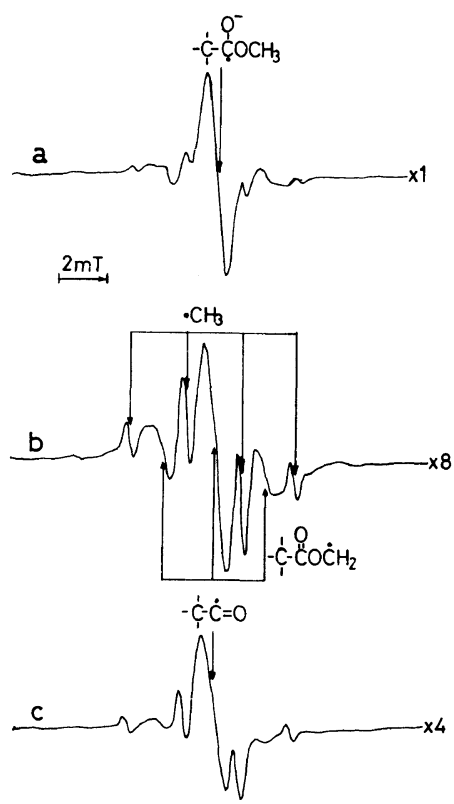

Figure 2. ESR spectra of $\gamma$-irradiated methyl pivalate recorded at $77 \mathrm{~K}$ (a) without further treatment, (b) after visible light-illumination for $30 \mathrm{~min}$, and (c) after subsequent UV light-illumination for $90 \mathrm{~min}$.

radicals generated by reaction,

$$
-\mathrm{COOC}_{2} \rightarrow-\dot{\mathrm{C}}=\mathrm{O}+\mathrm{HCHO}
$$

The above reactions were confirmed by using methyl pivalate as the model compound of PMMA. Figure 2 shows the ESR spectra of $\gamma$-irradiated methyl pivalate at $77 \mathrm{~K}$. A singlet at the center of the spectrum in Figure $2 a$ is due to the anion radicals of methyl pivalate. ${ }^{15}$ As shown in Figure 2b, the anion radicals are disappeared by illuminating the sample with visible light, and a part of the anion radicals are converted to methyl radicals. A triplet due to $\mathrm{C}\left(\mathrm{CH}_{3}\right)_{3} \mathrm{COOC}_{2}$ radicals and a singlet due to $\mathrm{C}\left(\mathrm{CH}_{3}\right)_{3} \mathrm{C}=\mathrm{O}$ radicals are also observed in Figure 2b. As shown in Figure 2c, UV irradiation of the visible light-illuminated sample increases the singlet $\mathrm{C}\left(\mathrm{CH}_{3}\right)_{3} \mathrm{C}=\mathrm{O}$ radicals at the expense of the triplet $\mathrm{C}\left(\mathrm{CH}_{3}\right)_{3}$ $\mathrm{COOCH}_{2}$ radicals. Thermal annealing of the UV-irradiated sample merely causes the decrease of the spectral intensity without 
change of the spectral shape, because the radical species recombine with each other before thermal conversion to another radicals. The UV-irradiation of methyl pivalate without $\gamma$-irradiation gives the ESR spectrum similar to that in Figure 2c, though the spectral intensity is much lower than that of the $\gamma$-irradiated one.

Since the $-\mathrm{COOC} \mathrm{H}_{2}$ and $-\dot{C}=\mathrm{O}$ polymer radicals are quantitatively converted to the scission-type radicals and the yield of the scission-type radicals is not affected by the $\mathrm{UV}$-irradiation, it is reasonable to assume that the $-\mathrm{COOCH}_{2}$ and $-\mathrm{C}=\mathrm{O}$ polymer radicals are thermally converted to the same kind of radical species and the resultant radical is then spontaneously converted to the scission-type radical. Taking the fact that $\mathrm{CO}$ and $\mathrm{HCHO}$ are the main stable products detected after the $\gamma$-irradiation of PMMA ${ }^{16,17}$ into account, the $-\mathrm{C}=\mathrm{O}$ and the $-\mathrm{COOCH}_{2}$ radicals may be converted to the scission-type radicals by reactions,

$$
\begin{aligned}
& -\mathrm{CH}_{2}-\mathrm{C}\left(\mathrm{CH}_{3}\right)\left(\mathrm{COOC}_{2}\right)-\mathrm{CH}_{2}- \\
& \quad \rightarrow \mathrm{CH}_{2}-\mathrm{C}\left(\mathrm{CH}_{3}\right)-\mathrm{CH}_{2}-+\mathrm{CO}+\mathrm{HCHO} \\
& -\mathrm{CH}_{2} \mathrm{C}\left(\mathrm{CH}_{3}\right)(\dot{\mathrm{C}}=\mathrm{O})-\mathrm{CH}_{2}- \\
& \quad \rightarrow \mathrm{CH}_{2}-\mathrm{C}\left(\mathrm{CH}_{3}\right)-\mathrm{CH}_{2}-+\mathrm{CO} \\
& -\mathrm{CH}_{2}-\mathrm{C}\left(\mathrm{CH}_{3}\right)-\mathrm{CH}_{2}-\rightarrow-\mathrm{CH}_{2}-\mathrm{C}\left(\mathrm{CH}_{3}\right)=\mathrm{CH}_{2} \\
& \quad+\mathrm{C}\left(\mathrm{CH}_{3}\right)\left(\mathrm{COOCH}_{3}\right)-\mathrm{CH}_{2}-
\end{aligned}
$$

Although the anion radicals of PMMA have been detected, no ESR spectrum of PMMA cation radicals, counterpart of the anion radicals, has not been observed at $77 \mathrm{~K}$. Since the cation radicals of carboxylic esters are known to be thermally converted to neutral radicals via intramolecular or intermolecular proton transfer to surrounding molecules, ${ }^{18}$ we tried to detect the ESR spectrum of PMMA cation radicals by $\gamma$-irradiating the polymer at $4.2 \mathrm{~K}$. However the ESR spectrum after the irradiation was the same as that in Figure 1a. We therefore conclude that the conversion of the cation radicals to neutral radicals,

\section{$\mathrm{PMMA}^{++}$

$$
\begin{aligned}
\rightarrow & \mathrm{H}^{+}+-\mathrm{C}\left(\mathrm{CH}_{3}\right)\left(\mathrm{COOCH}_{2}\right)-\mathrm{CH}_{2}-, \\
& -\mathrm{C}\left(\mathrm{CH}_{3}\right)\left(\mathrm{COOCH}_{3}\right)-\dot{\mathrm{C}} \mathrm{H}_{-}^{-}
\end{aligned}
$$

is quite fast even at $4.2 \mathrm{~K}$.

The mechanism of $\gamma$-ray induced degradation of PEtMA is essentially the same as that for PMMA. Figure 3 shows the ESR spectra of the $\gamma$-irradiated PEtMA. A broad singlet in Figure $3 \mathrm{a}$ can be assinged to anion radicals $-\mathrm{COOC}_{2} \mathrm{H}_{5}{ }^{\cdot-}$. Illumination of the sample with visible light for 30 min causes the complete disappearance of the anion radicals and the concomitant increase of ethyl radicals. A broad quintet in Figure $3 \mathrm{~b}$ is due to neutral radicals $-\mathrm{COOCHCH}_{3}$. Since no methyl radical is detected, it is evident that the photo-induced elimination of alkyl groups takes place only at the side-chain alkyl-ester group. Photo-induced elimination of $\alpha$-methyl groups once postulated ${ }^{10}$ seems improbable

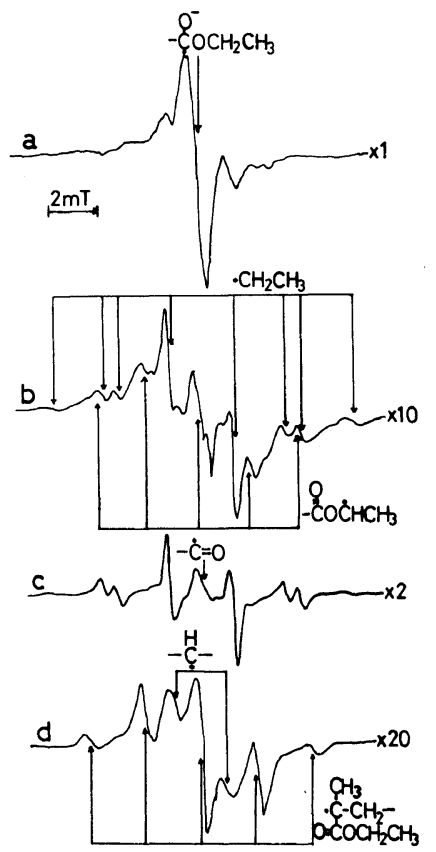

Figure 3. ESR spectra of $\gamma$-irradiated PEtMA recorded at $77 \mathrm{~K}$ (a) without further treatment, (b) after visible light-illumination for $30 \mathrm{~min}$, (c) after subsequent UV light-illumination for $90 \mathrm{~min}$, and (d) after subsequent thermal annealing to room temperature for $10 \mathrm{~min}$. 
both for the $\gamma$-irradiated PMMA and PEtMA. As shown in Figure 3c, UV-irradiation of the visible light-illuminated sample leads to the conversion of the $-\mathrm{COOC}^{-} \mathrm{HCH}_{3}$ radicals to acyl-type radicals by reaction,

$$
-\mathrm{COOCHCH}_{3} \rightarrow-\mathrm{C}=\mathrm{O}+\mathrm{CH}_{3} \mathrm{CHO}
$$

The UV-irradiation also leads to the increase of the ethyl radicals, which is due to the direct photolysis of PEtMA. Upon annealing the sample to room temperature, both the $-\mathrm{COOCHCH}_{3}$ and the $-\dot{\mathrm{C}}=\mathrm{O}$ radicals convert to scission-type radicals $\mathrm{C}\left(\mathrm{CH}_{3}\right)\left(\mathrm{COOC}_{2} \mathrm{H}_{5}\right)$ $\mathrm{CH}_{2}-$ with the ESR spectrum identical to that for PMMA. ${ }^{1,2}$

The formation of the ethyl radicals by the direct photolysis of PEtMA was confirmed by UV-irradiating the PEtMA sample without $\gamma$-irradiation. The direct UV-irradiation leads to the formation of the ethyl radicals, the $-\mathrm{COOCHCH}_{3}$ radicals, the acyl-type radicals and probably $-\dot{\mathrm{C}} \mathrm{H}$-radicals. The yields of the ethyl radicals and the acyl-type radicals monotonously increase with increasing the time of the UV-irradiation, whereas the yield of the - $\mathrm{COOC}^{-} \mathrm{HCH}_{3}$ radicals reaches a plateau value. The ESR spectrum after 90 min UV-irradiation is similar to that in Figure 3c, though the relative ESR intensity of the ethyl radicals is much higher. These results indicate that the $-\mathrm{COOC}^{-} \mathrm{HCH}_{3}$ radicals generated by the $\gamma$ - or the UV-irradiations convert to the acyl-type radicals by the action of the UV light.

The radical reactions taking place in $\gamma$-irradiated ethyl pivalate, a model compound of PEtMA, are essentially the same as those for PEtMA. Figure 4 shows the ESR spectra at $77 \mathrm{~K}$ of $\gamma$-irradiated ethyl pivalate. A central broad singlet in Figure $4 \mathrm{a}$ is due to anion radicals $\mathrm{C}\left(\mathrm{CH}_{3}\right)_{3} \mathrm{COOCH}_{2} \mathrm{CH}_{3}{ }^{--}$. A part of the anion radicals converts to ethyl radicals by illuminating the sample with visible light. A broad quintet is due to $\mathrm{C}\left(\mathrm{CH}_{3}\right)_{3} \mathrm{COOCHCH}_{3}$ radicals. $\mathrm{UV}$-irradiation of the sample increases
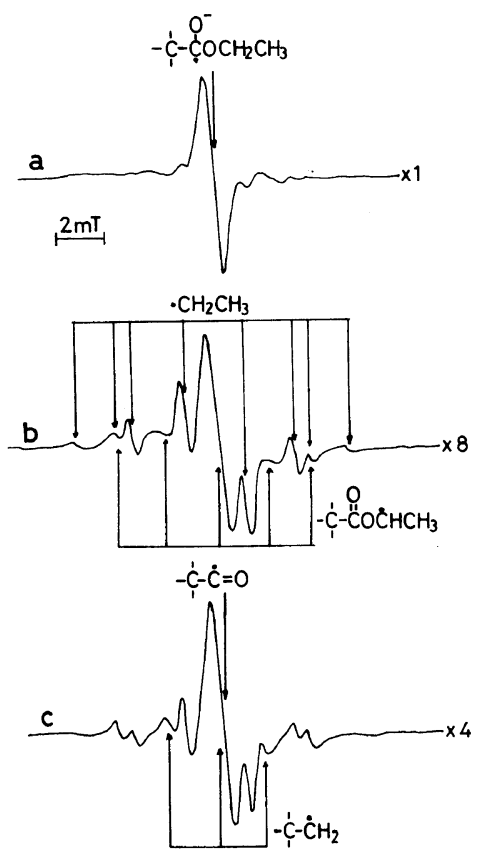

Figure 4. ESR spectra of $\gamma$-irradiated ethyl pivalate recorded at $77 \mathrm{~K}$ (a) without further treatment, (b) after visible light-illumination for $30 \mathrm{~min}$, and (c) after subsequent UV light-illumination for $90 \mathrm{~min}$.

the singlet $\mathrm{C}\left(\mathrm{CH}_{3}\right)_{3} \dot{\mathrm{C}}=\mathrm{O}$ radicals at the expense of the quintet $\mathrm{C}\left(\mathrm{CH}_{3}\right)_{3} \mathrm{COOC}_{\mathrm{CHCH}}$ radicals. The UV-irradiation also induces the decomposition of ethyl pivalate into ethyl radicals and triplet $\mathrm{CH}_{2}\left(\mathrm{CH}_{3}\right)_{2} \mathrm{COOC}_{2} \mathrm{H}_{5}$ radicals. ${ }^{18}$

It is concluded from the present study that the main-chain scission of poly(alkyl methacrylate)s is induced by the conversion of ester-alkyl radicals to tertiary alkyl radicals followed by the $\beta$-scission of the tertiary radicals. The ionic species remaining at $77 \mathrm{~K}$ have no primary importance for the degradation of the polymers, because the yield of the ester-alkyl radicals is scarcely changed by photobleaching the anion radicals with visible light. The reaction scheme for the ionizing radiationinduced degradation of PMMA and PEtMA are summarized as follows; 
M. TANaKa, H. Yoshida, and T. IChIKaWA

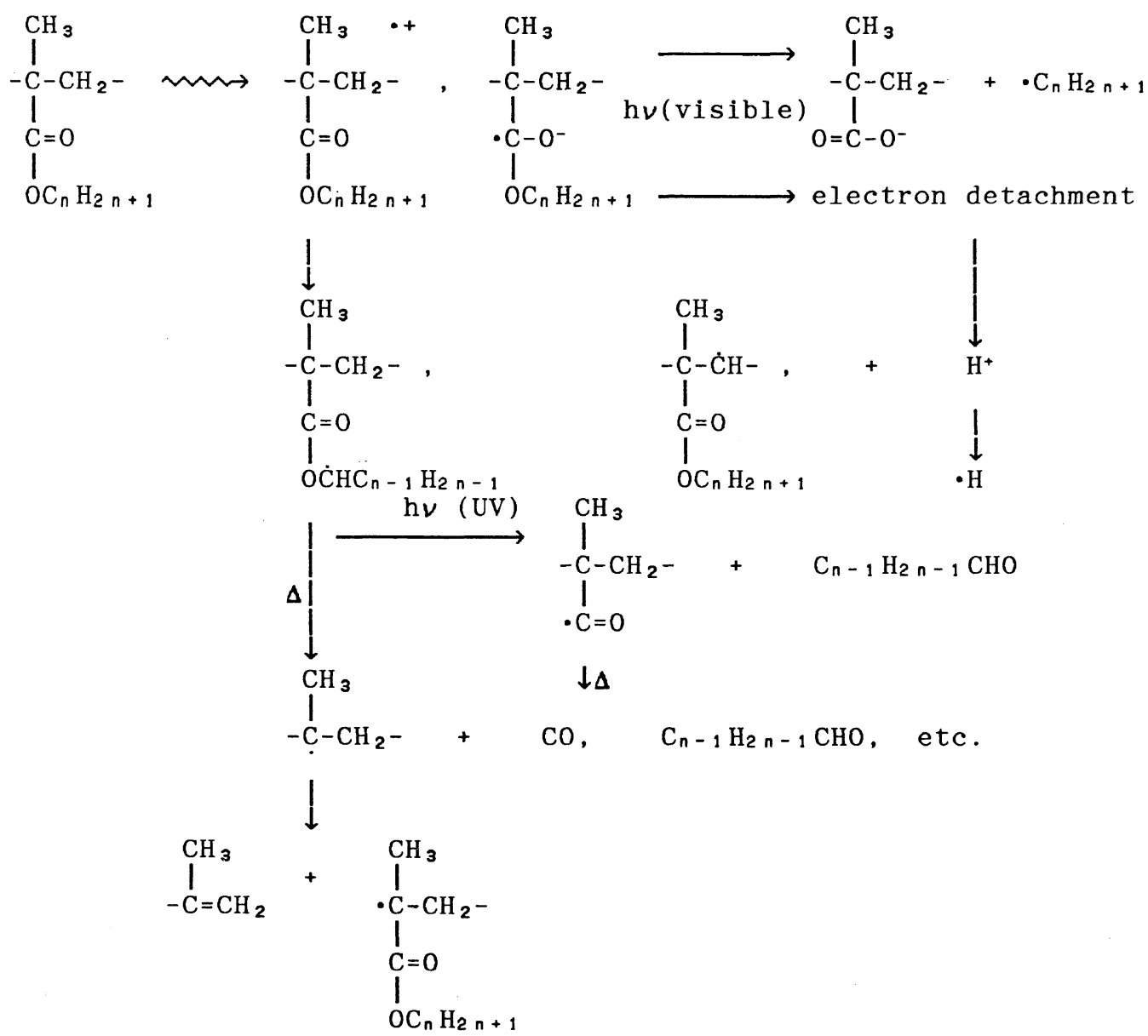

The $-\mathrm{COOC} \mathrm{HC}_{n-1} \mathrm{H}_{2 n-1}$ and the - $\mathrm{CH}-$ radicals may also be generated by non-ionic processes such as the direct $\mathrm{C}-\mathrm{H}$ bond scission of excited poly(alkyl methacrylate)s and the abstraction of $\mathbf{C}-\mathrm{H}$ hydrogens by hydrogen atoms. The hydrogen atoms generated by the reaction of protons with photo-ejected electrons also recombine with these neutral polymer radicals. The yield of the neutral polymer radicals is therefore scarcely changed by photobleaching the anion radicals.

\section{REFERENCES}

1. M. Iwasaki and Y. Sakai, J. Polym. Sci., A-1, 1537 (1969).

2. V. Deniz, O. Güven, and T. Ozbey, Radiat. Phys.
Chem., 26, 33 (1985).

3. V. Deniz, O. Güven, and T. Ozbey, Radiat. Phys. Chem., 26, 39 (1985).

4. G. Geuskens, D. Fuld, and C. David, Makromol. Chem., 160, 135 (1972).

5. A. Torikai, T. Asai, T. Suzuki, and Z. Kuri, J. Polym. Sci., Polym. Chem. Ed., 13, 797 (1975).

6. A. Torikai, H. Kato, and Z. Kuri, J. Polym. Sci., Polym. Chem. Ed., 14, 1065 (1976).

7. A. Torikai and R. Kato, J. Polym. Sci., Polym. Chem. Ed., 16, 1487 (1978).

8. A. Torikai and S. Okamoto, J. Polym. Sci., Polym. Chem. Ed., 16, 2689 (1978).

9. A. Torikai and H. Mishina, J. Polym. Sci., Polym. Chem. Ed., 19, 2297 (1981).

10. M. Tabata, G. Nilsson, and A. Lund, J. Polym. Sci., Polym. Chem. Ed., 21, 3257 (1983).

11. M. Ogasawara, M. Tanaka, and H. Yoshida, J. Phys. Chem., 91, 937 (1987).

12. T. Ichikawa and H. Yoshida, J. Polym. Sci., Polym. Chem. Ed., 28, 1185 (1990). 
Radical Reaction in $\gamma$-Irradiated Poly(alkyl methacrylate)s

13. R. L. Huddson and F. Williams, J. Phys. Chem., 82, 967 (1978).

14. J. E. Bennet and B. Mile, J. Chem. Soc., Faraday Trans. 1, 67, 1587 (1971).

15. Y. Nakajima, S. Sato, and S. Shida, Bull. Chem. Soc. Jpn., 42, 2132 (1969).

16. W. Burlandt, D. Green, and C. Taylor, J. Appl. Polym. Sci., 1, 296 (1959).

17. A. Todd, J. Polym. Sci., 42, 223 (1960).

18. P. B. Ayscough and J. P. Oversby, J. Chem. Soc., Faraday Trans. 1, 68, 1153 (1972). 